International Journal of Engineering \&Technology, $7(1.8)(2018) 164-167$
International Journal of Engineering \& Technology
SPC
Website: www.sciencepubco.com/index.php/IJET
Research paper

\title{
IOT And Big Data Analytics In E-Learning: A Technological Perspective and Review
}

\author{
S.Kusuma ${ }^{1}$, D. Kasi Viswanath ${ }^{2}$ \\ ${ }^{I}$ Assistant Professor, Department of CSE, Madanapalle Institute of Technology \& Science \\ ${ }^{2}$ Assistant Professor, Department of CSE, Madanapalle Institute of Technology \& Science
}

\begin{abstract}
The internet of things \& Big data analytics in eLearning brings tremendous challenges \& opportunities to educational institutions \& students. In recent trends, the growth of Pervasive computing, Social media, evolving IoT capabilities, technologies such as cloud computing, and big data and analytics are improving the core values of teaching and conducting research but also instilling a new digital culture and developing an IoT-centric society. The primary purpose of this paper is to provide an impact of IoT \& Big data analytics in the area of E-learning and study on different E-learning approaches.
\end{abstract}

Keywords : Internet of things(IoT), Big data analytics, Pervasive computing , E-Learning.

\section{Introduction}

ELearning focuses on usage of technology in the field of education and learning. E learning provides an enabling platform by virtual classrooms of which the learners can upgrade their knowledge without traditional learning methodologies.

In the current scenario, the rapid growth of information and communication technology has led to the alphabet "e" becoming the symbol of this latest age of information technology. The alphabet "e" is used as abbreviation for electronics. Thus, words prefixed with "e" are currently emerging in every second field, like e- learning, e-health, e- business, e-government and many more. The world is being dominated by globalization, networking and information technology has reached its peak, e-learning plays a vital role in the field of education [1].

Social media in eLearning also plays a major role for learner centric. Now a day's many of them rely on social media to promote courses information, training programs, learning materials \& to enrol new courses. The most popularly used to promote are YouTube, LinkedIn, Twitter, Facebook \& Google plus. The below statistic shows the number of social media internet users in india [37].

\section{Definitions}

\section{A. Big Data}

"Big Data" means enormous volumes of data. The data can be divided as structured data and unstructured data. Various methods are applied to collect these data. These data can be analysed and designed in such a way to fit the institution or e-Learning professionals. With the availability of data, opportunity can be created to determine how the e-learner can acquire various information for problems that may exist. Advanced computing technologies and with other technical tools the data can be tailored for specific usage which benefits the requirement. Big data are used for studying the trends of the industry, user behaviour pattern by applying logical association within data set. Both big data and analytics play a vital role which impacts ELearning [2].

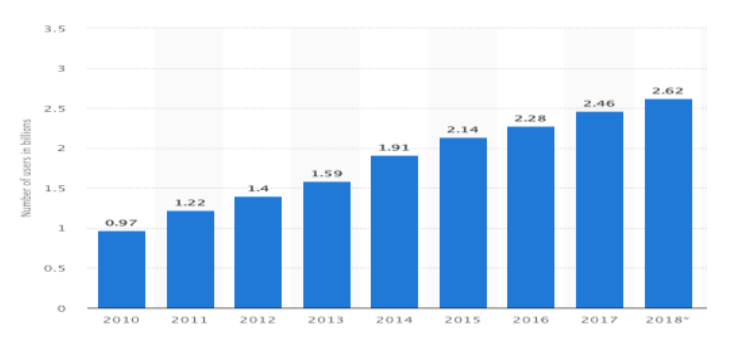

Fig 1: Incremental growth of Internet users

\section{B. Internet of things}

IoT influences education in many ways. It is this asset intelligence that enables institutions to make more informed decisions in an effort to improve student learning experiences, operational efficiency and campus security. It is this asset intelligence that enables institutions to make more informed decisions in an effort to improve student learning experiences, operational efficiency and campus security and many more [3].

\section{Pervasive computing}

Pervasive computing, also called ubiquitous computing. Ubiquitous computing leads to ubiquitous learning. Technology 
provides abundant opportunities for sharing information, constructing knowledge and stimulating personal growth. The term ubiquitous learning means that we are going to change the "culture of learning", that we are being continually surrounded by and absorbed in learning experiences. Handhelds can be used anywhere inside an educational institution or outside. Handhelds can provide access to computing at the places where students' activities and learning occur [4].

\section{E-Learning through Cloud computing, IoT, Big data analytics}

This section presents literature survey on ELearning process. Many learning methods are introduced in Education system like selflearning, learning though cloud computing, Lifelong learning environment, virtual E-Learning, Ubiquitous learning, Mobile learning, IoT based learning. We also presented feasibility study and security. Table 1 summarizes the detailed literature Survey of E-Learning approach.

Table 1: Literature Survey on E-Learning

\begin{tabular}{|c|c|c|}
\hline Sl.no & Analysis & Approach \\
\hline 1. & Self-learning [9] & $\begin{array}{l}\text { Bayesian framework algorithm which supports autonomous } \\
\text { learning }\end{array}$ \\
\hline 2. & Security and Privacy[10] & Review and classification \\
\hline 3. & Applications [11] & $\begin{array}{l}\text { IoT potentials to transform education and to improve student } \\
\text { performance. }\end{array}$ \\
\hline 4. & Cloud Computing [12] & $\begin{array}{l}\text { Heterogeneous e-learning components through IaaS, PaaS and } \\
\text { SaaS cloud service models. }\end{array}$ \\
\hline 5. & Internet of Things (IoT)[13][36] & Implementation,research challenges and open problems \\
\hline 6. & A Feasibility Study on Developing IoT/M2M [14] & Created a suitable IoT/M2M curriculum for our students. \\
\hline 7. & A comprehensive study of parameters [15] & $\begin{array}{l}\text { The impact of several parameters of the physical environment } \\
\text { in a classroom }\end{array}$ \\
\hline 8. & Ubiquitous Teaching and Learning System [16] & $\begin{array}{l}\text { Personalised Ubiquitous eTeaching \& eLearning (UTiLearn) } \\
\text { framework. }\end{array}$ \\
\hline 9. & Lifelong learning environment [17] & Established learning analytics \\
\hline 10. & E-learning based on crowdsourcing [18] & Described a prototype \\
\hline 11. & Task-Based Language Learning [19] & $\begin{array}{l}\text { Investigation of using wearable and Internet-of-Things (IoT) } \\
\text { technologies. }\end{array}$ \\
\hline 12 & Big Data Analysis [20] & Introduced a framework for traditional e- learning systems \\
\hline 13. & ETesting - Virtual eLearning Space [21] & Presented a architecture of an eTesting system \\
\hline 14 & Knowledge Networks in the Cloud [22] & "learning about how to learn to learn": MOOCs.. \\
\hline 15. & Individualized Learning Activities [23] & Proposed an integrated adaptive framework. \\
\hline 16. & Cloud E-learning [24] & Usage of cloud computing in holistic \\
\hline 17 & Learning internet of things[25] & $\begin{array}{l}\text { Presented a model based on a web-service oriented cloud } \\
\text { platform. }\end{array}$ \\
\hline 18 & Mobile Learning [26] & Review of the framework on mobile learning. \\
\hline 19 & IoT as educational tool [27] & $\begin{array}{l}\text { Integrated development to lead to a websockets-supported } \\
\text { system. }\end{array}$ \\
\hline 20 & Future Internet of Things [28] & Described about the teaching methodology \\
\hline 21 & Teaching and experimental research [29] & $\begin{array}{l}\text { Featuring network interfaces: from the hardware perspective \& } \\
\text { software perspective }\end{array}$ \\
\hline 22 & Fog Computing and Big Data Streams [30] & Proposed big stream and fog-based educational framework. \\
\hline 23 & Secure integration of IoT and Cloud Computing [31] & Survey on security challenges \\
\hline 24 & Robots for Teaching [32] & $\begin{array}{l}\text { Introduced a framework of methodology for robotics-oriented } \\
\text { teaching. }\end{array}$ \\
\hline 25 & Adaptive Learning[34] & Highlights a number of theoretical and technical issues. \\
\hline 26 & Collaborative Learning [36] & Demonstrated the implementation of project-based learning. \\
\hline
\end{tabular}

\section{IoT \& Big Data Analytics in E-learning:}

The Internet of Things \& Big data analytics is changing everything, and eLearning is no exception. It is this asset intelligence that enables eLearning Professionals to customize the eLearning experience to provide learners with more informative, engaging, and engaging eLearning courses.

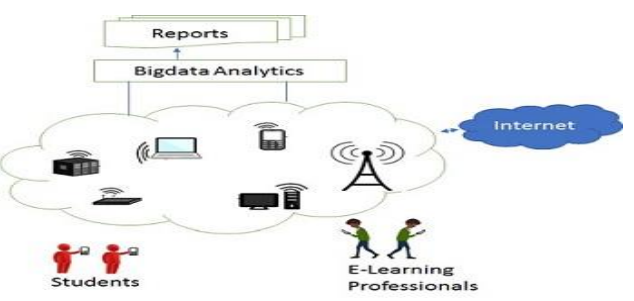

Fig 2: Analytics \& IoT Centric E-Learning

The main objective is to achieve optimized ELearning platform for learners \& professionals. The Analytics \& IoT centric system for e-learning includes the platform devices, Big data analytics management and the supporting software and tools. The network 
infrastructure includes of ELearning Virtual database, Visualization technique, distributed resources and a high-speed network. The main components of e-learning platform are Big Data Analytics application platform and IoT infrastructure of network. The IoT Centric management aspect involves managing the online courses, Modules, the resources and the process of learning. Some of the supporting tools and software to perform Big Data analytics for processing data related to Instructor requirements. This also helps to assess the platform in different fields. The IoT on the smart devices is about the data. The data generated from IoT sensors are communicated through network and the integrated data are analysed through big data analytics as represented in IoT and Big data functional view in ELearning [8]. This new trend influences E-learning in Six ways [5][6].

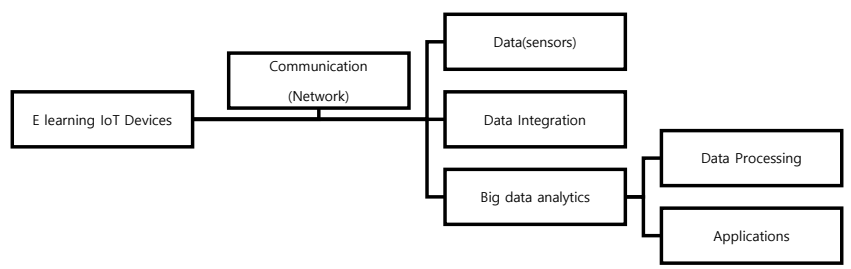

Fig 3: IoT and Big data analytics Functional View

\section{A. Learners Will Utilize Content Distinctly \& Analyses Feedback.}

In future, most of the learners and course providers will from prefer for video tutorials and need to optimize for mobile. Video is easily integrated into small IoT-enabled devices and can be more effective than the written word, so eLearning students and professionals will have to change the way they deliver content. The advantage of video-based learning is easy to create \& upload, distribution is easy over the network \&cost-effective. Big data analytics offers online surveys and feedback regarding the effectiveness of eLearning courses and can assess the learners where need to be improved.

\section{B. The Flexible Design For E-Learning Courses Will Survive and Thrive}

Big data analytics in ELearning courses gives the opportunity for professionals to analyse how the learners are gaining information and can predict which works best for them in terms of content and delivery helps in designing high quality modules to meet the individual needs of the learner. The Flexible design helps to succeed in this ever-evolving digital landscape.

\section{Refinement of Testing \& Tracking Learner Patterns}

With internet access instructors test students in portal this will change the pattern of question-and-answer exams to researchbased projects. Rather than answering multiple choice questions with the IoT centric system students will have to use the internet to spot answers. As an eLearning professional, this will be the best way to Assess your students. With the use of big data analytics, eLearning instructors can track how the learner performed on a test or challenge throughout the entire eLearning module, from start to finish.

\section{Expectations \& Estimating of the ELearning system will change.}

The IoT and Big data analytics will change the expectations of the people, this system will become the new model to access the information. As eLearning professionals, it's essential design the course more interactive and convenient to attract students when introducing any new course to standout unique from other courses. Big data analytics gives us a chance by learning analytics and academic analytics to analyse how the learners are responding to the courses provided by us. We can also estimate the efficiency of which course delivery method made students to grasp information. This information can then be worn to take our eLearning design to the next level.

\section{E. Targeting Effective ELearning Strategies will lead in new jobs and reaches goals.}

ELearning professionals need to focus on introducing new curricula for learners with the rise of development of IoT centric $\&$ Big data analytics in education sector. This change in advance learning will offer new career opportunities for students in recent trends. Big data analytics analyses which eLearning strategies are working and gives which strategies aren't helpful in terms of eLearning goal achievement.

\section{F. IoT And Analytics will achieve global job competence.}

E-Learning in IoT is a network enabled transfer of knowledge which is allowing learners to get close together by connecting everyone to the web through virtual classrooms. In future jobs will become more competitive, learners need specific skills to survive. ELearning professionals with the big data analytics may help their students in incorporating different learning materials to make them industry ready in competitive career fields.

\section{Conclusion}

E-learning is the globalization of education system. Due to advancement in technology, it's incredible to imagine where the world will be after another 20 years. Application of IOT \& big data analytics in eLearning will achieve the revolutionary development. This combination also reshapes customized learning environments to the learners, can reduce failures and it's a conquest situation for both the eLearning professionals and the learners.

\section{References}

[1] Himanshu Agarwal,G.N.Pandey,"Impact of E-Learning in Education", International Journal of Science and Research (IJSR) ISSN (Online): 2319-7064.

[2] Pranav Murali, "Big Data and E-Learning", International Journal of Scientific and Research Publications, Volume 7, Issue 8, August 201759 ISSN 2250-3153

[3] http://edtechreview.in/trendsinsights/trends/2855- internet-ofthings-iot-in-education.

[4] Mona Laroussi,"New Elearning services based on mobile and ubiquitous computing: UBI-Learn project". 
[5] https://elearningindustry.com/internet-of-things-is- changingelearning-6-ways.

[6] https://elearningindustry.com/Bigdata-eLearning.

[7] D.KasiViswanath, S.Kusuma \& Saroj Kumar Gupta "Cloud Computing Issues and Benefits Modern Education" Global Journal of Computer Science and Technology, Cloud\& Distributed Volume 12 Issue 10 Version 1.0 July 2012

[8] https://www.semiwiki.com/forum/content/5383-how- artificialintelligence-will-kickstart-internet-things.html.

[9] "Enabling self-learning in dynamic and open IoT environments ":Arun kishore Ramakrishnana,*, Davy Preuveneersa, Yolande Berbersa aiMinds-DistriNet, KU Leuven, Celestijnenlaan 200A, B-3001 Leuven, Belgium. ScienceDirect Procedia Computer Science 32 (2014) $207-214$

[10] Security and Privacy in m-Learning and Beyond: Challenges and State-of-the-art ,Georgios Kambourakis Aegean Karlovassi, Samos, International Journal of u- and e- Service, Science and Technology Vol. 6, No. 3, June, 2013

[11] Applications of Internet of Things in E-Learning Prof. Dr.SrisakdiCharmonman1Pornphisud Mongkhonvanit2 ,Vo Ngoc Dieu3 and Niek van der Linden4.International Journal of the Computer, the Internet and Management Vol.23 No.3 (September-December, 2015) pp. 1-4 .

[12] Facta Universitatis Series: Electronics And Energetics Vol. 27, No 3, September 2014, Pp. 339 - 357 Doi: 10.2298/Fuee1403339r Harnessing Cloud Computing Infrastructure For E-Learning Services Božidar Radenković, Marijana Despotović-Zrakić, Zorica Bogdanović, Vladimir Vujin, Dušan Barać .

[13] Internet of Things (IoT): A Vision, Architectural Elements, and Future Directions Jayavardhana Gubbi,a Rajkumar Buyya,b* Slaven Marusic,aMarimuthu Palaniswamia.

[14] A Feasibility Study on Developing IoT/M2M Applications over ETSI M2M Architecture Fuchun Joseph Lin, Yi Ren and Eduardo Cerritos.

[15] A comprehensive study of parameters in physical environment that impact students' focus during lecture using Internet of Things Ana Uzelac $\Uparrow$, Nenad Gligoric, Srdjan Krco University of Belgrade, Faculty of Organizational Sciences, Jove Ilica 154, Belgrade, Serbia

[16] Rashid Mehmood1,Furqan Alam2, Nasser N. Albogami2, Iyad Katib2,Aiiad Albeshri2, And Saleh M. Altowaijri3 :" UTiLearn: A Personalised Ubiquitous Teaching and Learning System for Smart Societies"

[17] Hsu-Chen Cheng, Wen-Wei Liao,"Establishing An Lifelong Learning Environment Using Iot And Learning Analytics"

[18] Journal of Universal Excellence, "Model Of Smart Environment For E-Learning Based On Crowdsourcing" Konstantin Simić*,Jove Ilića Marijana Despotović, Igor Đurić , Aleksandar Milić , Nikola Bogdanović.

[19] IEEE TRANSACTIONS "Introducing IoT and Wearable Technologies into Task-Based Language Learning for Young Children" Elena de la Gu ra, Vicente Lo pez Camacho, Luis Orozco-Barbosa, V ictor M. Brea Luja n, V ictor M. R. Penichet, and Mar ia Lozano Pe rez

[20] A Framework for Big Data Analysis in Smart Cities Hisham Elhoseny1 (Mohamed Elhoseny1,3 , A. M. Riad1, and Aboul Ella Hassanien2,3 @ Springer.

[21] Integration of eTesting in an IoT eLearning ecosystem - Virtual eLearning Space Konstantina Gramatova, Bulgaria ,Emil Doychev , stanimir stoyanov and vladimir valkanov .

[22] Connectivism and Interactionism Reloaded Knowledge Networks in the Cloud A Theoretical Approach to a Shift in Learning through Connectivism and MOOCs sabine Siemsen and Rainer Jansen Fernuniversität (c) Springer International Publishing Switzerland 2014

[23] Journal of Universal Computer Science, Navigation for Individualized Learning Activities in Ubiquitous Networking and IoT Environments Jian , Qun Jin ,Runhe Huang .

[24] Cloud E-learning for Mechatronics: CLEM Kuo-Ming Chao a,*, Anne E. James a, Antonios G. Nanos a, Jen-Hsiang Chen a, Sergiu-Dan Stanb, Ionut Munteanb, Giorgio Figliolinic, Pierluigi
Reac, Chedli B. Bouzgarroud, Pavel Vitliemove, Joshua Cooperf, Jürgen van Capelleg, Elsevier .

[25] "A Platform For Learning Internet Of Things" Zorica Bogdanović, Konstantin Simić, Miloš Milutinović, Božidar Radenković and Marijana Despotović- Zrakić .

[26] Khaddage, F., Müller, W., \& Flintoff, K. (2016). Advancing Mobile Learning in Formal And Informal Settings via Mobile App Technology: Ferial Khaddage1*, Wolfgang Müller2 and Kim Flintoff3.

[27] From RGB led laboratory to servomotor control with websockets and IoT as educational tool German Carro Fernandez, Elio Sancristobal Ruiz, Manuel Castro Gil, Francisco Mur Perez, IEEE .

[28] Educating Innovators of Future Internet of Things Evgeny Osipov, Laurynas Riliskis Department of Computer Science, Electrical and Space Engineering Lulea ${ }^{\circ}$ University of Technology 97187 Lulea ; Sweden \{Evgeny.Osipov, Laurynas.Riliskis\}@ltu.se

[29] Demonstration Abstract: Simply RIOT - Teaching and Experimental Research in the Internet of Things Oliver Hahm, Emmanuel Baccelli INRIA, France \{first.last\}@inria.fr Hauke Petersen, Matthias Wa $\ddot{\mathrm{h}}$ lisch FreieUniversitä̈ Berlin,Germany\{first.last $\} @$ fu-berlin.de Thomas C. Schmidt HAW Hamburg, Germany t.schmidt@ieee.org IEEE .

[30] Future Internet 2018, 10, 4; doi:10.3390/fi10010004 www.mdpi.com/journal/futureinternet A Virtual Learning Architecture Enhanced by Fog Computing and Big Data Streams ,Riccardo Pecori 1,2 ID

[31] Secure integration of IoT and Cloud Computing Christos Stergiou a, Kostas E. Psannis a,*, Byung-Gyu Kim b, BrijGuptachttp://dx.doi.org/10.1016/j.future.2016.11.031 Elsevier

[32] Burbaité, R. et al., Using Robots as Learning Objects for CSE

[33] Towards Internet of Things: Survey and Future Vision ,Omar Said Mehedi Masud,CS/ College of Computers and Information Technology Taif University Taif, Saudi Arabia. International Journal of Computer Networks (IJCN), Volume (5) : Issue (1) : 2013.

[34] "State Of The Art Of Learning Styles- Based Adaptive Educational Hypermedia Systems (LS-BAEHSS)", Ahmed AlAzawei1 and Atta Badii2 1School of Systems Engineering, Reading, RG6 6AY, UK a.al-azawei@student.reading.ac.uk 2School of Systems Engineering, Reading, RG6 6A Y , UK atta.badii@ reading.ac.uk

[35] eLearningPapers•ISSN:www.openeducationeuropa.eu/en/elearn ing_papers n.o 39 • July 2014 The Maker Movement. Implications of new digital gadgets, fabrication tools and spaces for creative learning and teaching

[36] Educational Robots for Internet-of-Things Supported Collaborative Learning Ignas Plauska1 and Robertas Damaševičius2 Kaunas University of Technology, ICIST 2014, CCIS 465, pp. 346-358, 2014. (C) Springer International Publishing Switzerland 2014

[37] https://www.statista.com/statistics/278407/number-of- socialnetwork-users-in-india. 